\title{
PARENTAL CORRELATES OF OFFSPRING SEX RATIO IN EURASIAN OYSTERCATCHERS
}

\author{
D. Heg, ${ }^{1,3}$ N. J. Dingemanse, ${ }^{1,4}$ C. M. Lessells, ${ }^{2}$ And A. C. Mateman ${ }^{2}$ \\ ${ }^{1}$ Zoological Laboratory, Kerklaan 30, P.O. Box 14, 9750 AA Haren, The Netherlands; and \\ ${ }^{2}$ Netherlands Institute of Ecology, Boterhoeksestraat 22, P.O. Box 40, 6666 ZG Heteren, The Netherlands
}

\begin{abstract}
We investigated hatchling and fledgling sex ratios in Eurasian Oystercatchers (Haematopus ostralegus) using random amplified polymorphic DNA markers. The overall hatchling ( $53 \%$ males, $n=374$ hatchlings from 177 broods) and fledgling ( $49 \%$ males, $n=$ 51) sex ratio did not differ significantly from unity. Hatchling and fledgling sex ratios were not correlated with laying date, clutch size, brood size, egg-laying sequence, territory quality, male age, or male breeding experience, but hatchling sex ratio was positively correlated with age and breeding experience of females $(0.05<P<0.075, n=71)$. Older females produced more sons irrespective of the position of the offspring in the egg-laying sequence. Fledging mass was not correlated with female age, so the Trivers and Willard (1973) hypothesis is unlikely to explain our results. Sons dispersed less than daughters, so the local resource competition hypothesis of Clark (1978) might apply. The adaptive significance of a malebiased sex ratio in clutches produced by older females is speculative because the costs and benefits of dispersing versus philopatric offspring to parents and offspring are largely unknown. Received 11 March 1999, accepted 27 April 2000.
\end{abstract}

IN BIRDS, departures from unity in hatchling sex ratios are rare (Clutton-Brock 1986, Frank 1990, Gowaty 1991). This is consistent with Fisher's equilibrium theory (1930), which predicts that parents should invest equally in sons and daughters. Nevertheless, in many species offspring sex ratios vary with parental attributes such as timing of breeding (Daan et al. 1996, Lessells et al. 1996), sequence in the clutch (Leroux and Bretagnolle 1996), maternal age (Blank and Nolan 1983), mate attractiveness (Ellegren et al. 1996, Svensson and Nilsson 1996), and territory quality (Appleby et al. 1997, Komdeur et al. 1997). However, some studies have found no correlation between sex ratios and parental attributes, despite the expectation of a relationship (Koenig and Dickinson 1996, Bradbury et al. 1997, Westerdahl et al. 1997).

Several non-mutually exclusive hypotheses have been advanced to account for variation in offspring sex ratios. Trivers and Willard (1973) proposed that maternal condition could affect the fitness of male and female offspring differ-

\footnotetext{
${ }^{3}$ Present address: Abteilung Ethologie, Zoologisches Institut, Universität Bonn, Kirschallee 1, D53115 Bonn, Germany. E-mail: d.heg@uni-bonn.de

${ }^{4}$ Present address: Netherlands Institute of Ecology, Boterhoeksestraat 22, P.O. Box 40, 6666 ZG Heteren, The Netherlands.
}

ently. For instance, if only mothers in good condition could produce high-quality offspring, and if mothers benefit more from high-quality sons than from high-quality daughters, mothers might adjust offspring sex ratio in relation to their body condition. In fact, the Trivers/ Willard argument applies more generally, and parents are expected to modify the sex ratio of their offspring in relation to any phenotypic or environmental variable that has a differential effect on fitness of sons versus daughters.

Hamilton (1967) showed that if the level of intrafamily competition for mates varies between sons and daughters, offspring sex ratios should be skewed toward the less-competing sex. Clark (1978) extended this hypothesis to include competition over resources between parents and their offspring. In this case, parents may benefit from producing an excess of the dispersing sex, which we term the local resource competition hypothesis. Alternatively, parents might benefit from producing the sex that enhances the fitness of the parents, for instance by assisting parents in raising future broods (e.g. Emlen et al. 1986, Lessells and Avery 1987, Komdeur et al. 1997). We call this the local resource enhancement hypothesis.

We investigated hatchling and fledgling sex ratios in Eurasian Oystercatchers (Haematopus ostralegus). Our aim was to explore whether hatchling sex ratio (determined using a molec- 
ular marker; Lessells and Mateman 1998) was correlated with environmental or parental variables. In particular, we investigated whether a relationship existed between offspring sex ratio and the dichotomy in territory quality that exists in some populations of this species. Pairs with nesting territories on the edge of the saltmarsh ("residents") are able to lead their chicks to adjacent feeding territories on the mudflats, whereas pairs with spatially separated nesting and feeding territories ("leapfrogs") are unable to do this and must fly with each food item from the mudflat to the nesting territory, where the chicks remain. As a result, residents fledge more chicks (on average, 0.67 vs. 0.19; Ens et al. 1995) at a higher fledging body mass (Ens et al. 1992, Heg 1999). If such differences in fledging mass have differential effects on the subsequent fitness of sons and daughters, residents and leapfrogs would be selected to produce different sex ratios. Other variables, including laying date (Harris 1969, Ens 1992, Ens et al. 1996, Heg 1999) and breeding experience (Ens et al. 1993, Heg 1999), also affect chick growth, and parents might similarly be expected to vary sex ratio in relation to these variables.

\section{Study Area And Methods}

Our study was conducted in the nature reserve "de Oosterkwelder," on the island of Schiermonnikoog. Hatchling and fledgling sex ratios were determined in 1995. The study area consists of about 130 ha of saltmarsh bordering the Wadden Sea, which is a huge area of tidal mudflats in The Netherlands. The area includes the study area described by Ens et al. (1992) and Heg et al. (2000).

Field methods.-Breeding Eurasian Oystercatchers (hereafter, "oystercatchers") have been individually color banded in the main study area (Heg et al. 2000) since 1983. It is therefore possible to make minimum estimates of age, the number of years spent breeding (breeding experience), and the number of years breeding with the current mate (pair-bond years).

In 1995, breeding attempts were monitored by regular territory and nest checks and by observations from blinds. We visited territories every other day to search for new nests and check existing nests for new eggs (clutch size is one to four eggs, ca. one egg daily). New eggs were individually marked with a waterproof marker, measured $( \pm 0.1 \mathrm{~mm})$, and weighed $( \pm 0.1 \mathrm{~g})$. Because egg predation is high during laying, many eggs may have been depredated before we found them, especially the first and second eggs of a clutch (Ens 1991). Hence, clutch size and laying order were underestimated in some cases. This might lead to biases that cannot be corrected, particularly because leapfrogs tend to lose more eggs to predators than do residents.

If the entire clutch is lost, females produce a replacement clutch within 8 to 12 days, usually in another nest. Overall, $63.6 \%$ of eggs were lost to predation, flooding, or trampling. For $43.6 \%$ of the eggs, two or more eggs were found on the same day. In these cases, laying order was assigned according to the remains of uric acid and blood on the eggshell of the newest-laid egg. The laying date of the first egg was estimated assuming a laying interval of $28 \mathrm{~h}$ between successive eggs; $5.1 \%$ of the eggs were found after clutch completion. In these latter cases, the laying date was estimated from the hatching date of the first-hatched chick, assuming an incubation period of 30 days for the first-hatched chick. The laying order of eggs could be determined based on mass loss of eggs due to partial incubation before clutch completion. We assumed that the first-laid egg had the lowest relative egg mass (mass/[0.489 $\times$ length $\times$ width $\left.{ }^{2}\right]$ ) at the time the nest was found (Strijkstra 1986). Laying dates used in the analysis were those of the first egg of each clutch ( $1=1$ January). Parents were identified at nests with chicks by reading color bands or by catching the birds at the nest.

We visited nests once or twice daily around the expected time of hatching. We used an inedible marker to mark the egg tooth of chicks that had begun to hatch so that newly hatched chicks found on subsequent visits could be assigned to an egg. Chicks from each brood hatched within one to two days. Hatching order was determined by frequent nest checks around hatching. Many chicks hatched almost simultaneously. When more than one chick hatched between nest visits and the hatching order could not be determined by the dampness of the down or the presence of the egg tooth, chicks were assigned the same hatching order (see Heg and van der Velde 2001).

We obtained 10 to $40 \mu \mathrm{L}$ of blood from the leg vein of hatchlings. Blood was stored in $500 \mu \mathrm{L} \mathrm{20 \%}$ DMSO and $4 \mathrm{M} \mathrm{NaCl}$ until DNA isolation. Chicks that died before blood sampling were frozen, and their DNA was isolated from body tissue. Of the eggs that survived the incubation period, $125(10.9 \%)$ failed to hatch. From these eggs, 74 embryos were collected, washed, and stored frozen. Unfortunately, DNA of sufficient quality could be isolated from only $31 \%$ of these embryos. Because of potential biases in scoring, we did not analyze the sex ratio of embryos.

Sex determination.-DNA was isolated from samples using phenol/chloroform after digestion with proteinase K (Sambrook et al. 1989; $n=150$ ), or with a DNA isolation kit (Gentra Systems; $n=224$ ). Sex was determined using PCR random amplified polymorphic DNA (RAPD) markers following Griffiths and Tiwari (1993). A suitable primer was found by 
screening 10-mer primers with DNA from adults sexed on the basis of egg-laying and copulation behavior (Heg et al. 1993, Lessells and Mateman 1998). Isogen primer 1567 from kit 2 (5' -CCGGCCGTCA-3') amplified a 0.55 kilobase female-specific fragment. This fragment was present in 56 known-sex females and absent in 57 known-sex males. The probability of finding this pattern if the amplified band was not a sex-specific fragment was $9.7 \times 10^{-35}$, indicating that the PCR band was a very reliable indicator of sex (see Appendix).

Statistical analysis.-We defined the sex ratio as the proportion of male young among chicks for which sex was determined. Analysis of parental effects on sex ratio were performed using the sex ratio of the brood as the unit of analysis. We used nonparametric statistics following Siegel and Castellan (1988). Logistic regressions were performed using SPSS PC+ V 5.1.2 (Norusis 1990). Territory quality (resident, creek leapfrog, or leapfrog; see Ens et al. 1992), clutch number (first vs. replacement clutch), clutch size (one to four), and brood size (one to four) were entered as categorical variables. SPSS converts these variables into dummy variables. Clutch size and brood size are interval variables, so polynomial contrasts were applied to account for this (Norusis 1990). Weighted logistic regressions were performed using GLIM with binomial errors and a logit link (Crawley 1993). Owing to low sample sizes, models with forward and backward selection of variables and interactions were constructed. The influence of the main effects did not change significantly depending on the type of model built, so we present results of the forward selection of variables. We tested for nonlinearity with laying date and hatching date by including a quadratic term, but all of these were nonsignificant. Significant results from logistic regressions were checked using randomization tests in which the proportion of 1,000 tests on randomized data giving a deviance greater than that observed was taken as an approximate probability value. To test for a departure from a binomial distribution of the proportion of males per brood, chicks were randomly reallocated between broods while maintaining the observed brood size distribution. Interactions between main effects are given only when they are significant. All tests are two-tailed.

\section{RESULTS}

Overall hatchling sex ratio.-In total, we sampled 374 chicks from 177 broods, including 156 entire broods. From the other 21 nests $(12 \%$ of nests, $5.8 \%$ of chicks), one or more chicks were not sampled. Clutch size at nests where eggs hatched varied from one to four $(n=1,32,101$, and 45 , respectively), with a mean of 3.06 eggs. The overall hatchling sex ratio was $52.9 \%$ males, which did not differ significantly from unity (binomial test, $P=0.28$ ). The mean sex ratio in broods was $53.8 \pm \mathrm{SE}$ of $2.8 \%$ males $(n$ $=177$ ). Altogether, 71 broods ( 175 chicks) were attended by a marked male and female parent.

Within-brood variation.-We performed $\mathrm{McNe}$ mar tests for each clutch size using pairwise comparisons of the sex of the chick for each combination of laying order (e.g. egg 1 vs. 2, egg 1 vs. 3 , egg 1 vs. 4 , egg 2 vs. 3 , etc.). Hence, one test was performed for clutch size two $(n=$ $18)$, three tests for clutch size three $(n=46,38$, and 45), and seven tests for clutch size four ( $n$ $=14,21,15,16,16,16$, and 18). Within all clutches, the sex of a hatchling appeared to be independent of the sex of the previous hatchling in the laying sequence (all $P$-values $>0.34$, corrected with Bonferroni adjustment). Therefore, we treated each hatchling as an unbiased sample of the sex ratio of the entire brood, and all broods, whether completely or incompletely sampled, were used in the subsequent analysis.

Between-brood variation.-In the analysis of brood sex ratios, the deviance of the null model $\left(\chi^{2}=238.25, \mathrm{df}=176, P<0.005\right)$ indicated significantly greater variation than expected from the binomial distribution (i.e. the sex ratio varied among broods), but this result was not confirmed by a randomization test $(P=0.507)$. Nevertheless, we investigated the relationship between sex ratio and a number of independent variables. The only parental variables that caused an almost significant change in the deviance were female age and breeding experience (these two variables were highly correlated). The proportion of males in the brood increased with female age and breeding experience (Table 1, Fig. 1). Hatchling sex ratio (\% males) was not related to territory quality (residents, $\bar{x}=53.9 \pm 4.3 \%, n=80$; creek leapfrogs, $\bar{x}=49.7 \pm 5.3 \%, n=51$; leapfrogs, $\bar{x}=$ $58.3 \pm 5.3 \%, n=46$ ), clutch size (two eggs, $\bar{x}=$ $56.3 \pm 7.4 \%, n=32$; three eggs, $\bar{x}=52.2 \pm$ $3.6 \%, n=100$; four eggs, $\bar{x}=54.7 \pm 5.6 \%, n=$ 44 ), or laying date (all $P$-values $>0.30$ ).

We investigated whether variation in sex ratio with female age was mediated via the order in which sons and daughters were produced in a clutch using logistic regression and including female age, territory quality, clutch size, and laying order $(n=174$ eggs in clutches of two to four). Female age was the only variable that approached significance $\left(\chi^{2}=3.4, \mathrm{df}=1, P=\right.$ 
TABLE 1. Hatchling sex ratio of Eurasian Oystercatchers in relation to environmental and parental variables. Results are from a weighted logistic regression with forward selection of terms. Changes in deviance are for the inclusion of that variable alone in the null model.

\begin{tabular}{|c|c|c|c|c|c|c|}
\hline \multirow[b]{2}{*}{ Variable } & \multicolumn{3}{|c|}{ All broods $(n=177)$} & \multicolumn{3}{|c|}{$\begin{array}{l}\text { Broods with both parents banded } \\
\qquad(n=71)\end{array}$} \\
\hline & $\Delta$ Deviance & $\mathrm{df}$ & $P$ & $\Delta$ Deviance & $\mathrm{df}$ & $P$ \\
\hline Null model deviance & 232.900 & 176 & & 98.000 & 70 & \\
\hline Clutch number & 0.578 & 1 & $>0.4$ & 0.117 & 1 & $>0.7$ \\
\hline Clutch size & 1.916 & 3 & $>0.5$ & 1.462 & 3 & $>0.6$ \\
\hline Brood size at hatching & 0.474 & 3 & $>0.9$ & 0.917 & 3 & $>0.8$ \\
\hline Laying date & 0.322 & 1 & $>0.5$ & 0.468 & 1 & $>0.4$ \\
\hline Territory quality ${ }^{\mathrm{b}}$ & 2.351 & 2 & $>0.3$ & 5.151 & 2 & $>0.1$ \\
\hline Female age & - & - & - & 3.200 & 1 & $<0.075$ \\
\hline Female breeding experience ${ }^{c}$ & - & - & - & 3.356 & 1 & $<0.075$ \\
\hline Male age & - & - & - & 1.975 & 1 & $>0.15$ \\
\hline Male breeding experience ${ }^{c}$ & - & - & - & 1.010 & 1 & $>0.3$ \\
\hline Pair-bond years ${ }^{c}$ & - & - & - & 0.042 & 1 & $>0.8$ \\
\hline
\end{tabular}

${ }^{\text {a }}$ First clutch or replacement clutch.

b Leapfrog, creek leapfrog, or resident.

${ }^{\mathrm{c}}$ Minimum estimates.

0.07). Notably, the interaction between laying order and female age was not significant $(P=$ 0.77).

Fledgling sex ratio.-In 1995, only 26 female and 25 male chicks fledged (49\% males), and the sex ratio was not related to the parents' breeding status, age, or breeding experience (logistic regression, all $P$-values $>0.10, n=37$ ). We also found no effects of clutch number, laying date, clutch size, or brood size at hatching on fledgling sex ratios.

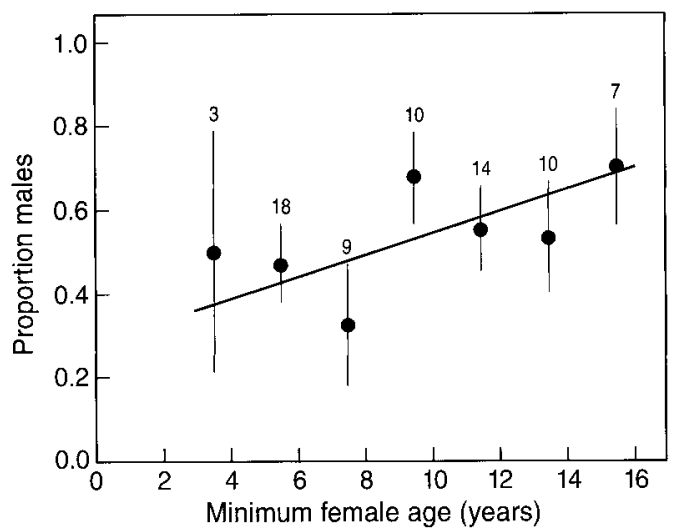

FIG. 1. Hatchling sex ratio of Eurasian Oystercatchers is positively related to female age $(0.05<P$ $<0.075)$. Values are $\bar{x} \pm$ SE for two age classes combined; sample sizes are above error bars. The line is the fitted logistic equation $1 /[1+\exp (Z)]$, where $Z$ $=0.885-0.107 \times$ female age.

\section{DisCUSSION}

We found no evidence that offspring sex ratio of Eurasian Oystercatchers varies with the dichotomy in territory quality, nor with other variables known to affect fledgling mass in this species. Instead, hatchling sex ratio tended to increase with female age and breeding experience in that older females produced more sons irrespective of clutch size or laying order. The Trivers and Willard (1973) hypothesis might explain these results, with the minimum requirement that older females also produced higher-quality males. In our study population, fledging mass had an important effect on the probability of offspring recruitment (Heg 1999), but fledging mass was not related to female age (1986 to 1995 data, $r=-0.021, n=216, P=0.76)$. Hence, the Trivers and Willard (1973) hypothesis is not likely to explain our results.

An alternative explanation is offered by the local resource competition hypothesis (Clark 1978), which predicts that parents should produce an excess of the dispersing sex when philopatric offspring compete with their parents. The probability of competition between parents and offspring is likely to decline with parental age, because older parents can expect fewer breeding seasons competing with their offspring as a result of lower survival of older breeders (Heg 1999). Hence, one might expect an increase in the production of the more philopatric sex with parental age. For offspring that set- 
tled in the study area, males dispersed $9.3 \pm 1.9$ territories $(n=18)$ and females $15.9 \pm 3.8$ territories $(n=8$; two females that settled on the mainland were excluded from analysis), indicating that sons are more philopatric than daughters (Mann-Whitney $U=36.5, P=0.01, n$ $=28$ ). However, it is questionable whether these recruits actually compete with their parents for resources (e.g. Brown and Brown 1993, Watson et al. 1994, Weatherhead and Montgomerie 1995), especially because we never observed sons and daughters that had settled adjacent to their natal territories (range 3 to 26 territories for sons and 5 to 35 territories for daughters). Additional measurements of the effect of offspring philopatry on the fitness of offspring and parents are needed to evaluate this idea more thoroughly.

Based on the above, we found no convincing adaptive explanation for a positive correlation between the proportion of sons produced and age of breeding females. An alternative nonadaptive hypothesis for the relationship between offspring sex ratio and parental age is highly debated in the literature on human sex ratios (e.g. Martin and Rademaker 1992, Martin et al. 1995). In humans, it is suspected that a change in the ratio of $X$ - and $Y$-bearing sperm results from physiological changes as males age. Because the female is the heterogametic sex in birds, physiological changes with female age might alter the sex ratio of offspring. However, critical tests have failed to support this hypothesis in humans (Martin and Rademaker 1992, Martin et al. 1995).

In conclusion, we could not attribute variation in offspring sex ratio to territory quality, which is a variable that has a profound effect on reproductive success, offspring quality, and recruitment in Eurasian Oystercatchers. Instead, we found a weak correlation between the hatchling sex ratio and female age. Additional data and experiments are needed to clarify whether offspring sex ratio is correlated with female age and whether locally recruited offspring decrease or enhance the inclusive fitness of their parents, and whether such an effect is sex dependent.

\section{ACKNOWLEDGMENTS}

$\mathrm{DH}$ and NJD were supported by the Life Sciences Foundation (SLW grants 805.30.164 and 805.33.321-P), which is subsidized by the Netherlands Organization for Scientific Research. We thank Irma de Groot, Astrid
Helmhout, Lies Klösters, Rutger Krijnen, and Foppe-Jan Voogd for help with blood sampling, and Jan Koenes and his crew for making the observation hides. Rob van Treuren and Louis van der Zande helped with DNA extractions, prepared DMSO tubes, and provided extracted DNA from adults. We thank Marijtje van Duijn for statistical advice. The population study was run by many people, of which Bruno Ens, Marcel Kersten, Jan Hulscher, and Alex Brenninkmeijer deserve special thanks. S. M. Yezerinac, R. Montgomerie, and an anonymous referee improved the manuscript and Franjo Weissing for helpful suggestions on estimating the probability of misclassifying the sex of chicks. We thank "Natuurmonumenten" for permission to work in their reserve. Permission for blood sampling was granted by the Facultaire Dierexperimenten Commissie, University of Groningen, license BG02295 to DH.

\section{Literature Cited}

Appleby, B. M., S. J. Petty, J. K. Blakey, P. Rainey, AND D. W. MACDONALD. 1997. Does variation of sex ratio enhance reproductive success of offspring in Tawny Owls (Strix aluco)? Proceedings of the Royal Society of London Series B 264: 1111-1116.

BlANK, J. L., AND V. NOLAN, JR. 1983. Offspring sex ratio in Red-winged Blackbirds is dependent on maternal age. Proceedings of the National Academy of Sciences USA 80:6141-6145.

Bradbury, R. B., P. A. Cotton, J. Wright, AND R. GRIFFITHS. 1997. Nestling sex ratio in the European Starling Sturnus vulgaris. Journal of Avian Biology 28:255-258.

BROWN, G. E., AND J. A. BROWN. 1993. Do kin always make better neighbours? The effects of territory quality. Behavioral Ecology and Sociobiology 33:225-231.

Clark, A. B. 1978. Sex ratio and local resource competition in a prosimian primate. Science 201: 163-165.

Clutton-Brock, T. H. 1986. Sex ratio variation in birds. Ibis 128:317-329.

CRAWLEY, M. J. 1993. GLIM for ecologists. Blackwell Scientific Publications, Oxford.

DaAn, S., C. DijKstra, And F. J. Weissing. 1996. An evolutionary explanation for seasonal trends in avian sex ratios. Behavioral Ecology 7:426-430.

Ellegren, H., L. Gustafsson, AND B. C. Sheldon. 1996. Sex ratio adjustment in relation to paternal attractiveness in a wild bird population. Proceedings of the National Academy of Sciences USA 93:11723-11728.

EMLEN, S. T., J. M. EMLEN, AND S. A. LEVIN. 1986. Sexratio selection in species with helpers-at-the nest. American Naturalist 127:1-8.

ENS, B. J. 1991. Guarding your mate and losing the egg: An oystercatcher's dilemma. Wader Study Group Bulletin 61 (Supplement):69-70. 
ENS, B. J. 1992. The social prisoner. Causes of natural variation in reproductive success of the Oystercatcher. Ph.D. dissertation, University of Groningen, Groningen, The Netherlands.

ENS, B. J., K. B. BRIGgs, U. N. SAFriel, AND C. J. SMit. 1996. Life history decisions during the breeding season. Pages 186-218 in The Oystercatcher. From individuals to populations (J. D. GossCustard, Ed.). Oxford University Press, Oxford.

Ens, B. J., M. Kersten, A. Brenninkmeijer, And J. B. HuLSCHER. 1992. Territory quality, parental effort and reproductive success of Oystercatchers (Haematopus ostralegus). Journal of Animal Ecology 61:703-715.

ENS, B. J., U. N. SAFriel, AND M. P. Harris. 1993. Divorce in the long-lived and monogamous Oystercatcher, Haematopus ostralegus: Incompatibility or choosing the better option? Animal Behaviour 45:1199-1217.

Ens, B. J., F. J. Weissing, AND R. H. DRent. 1995. The despotic distribution and deferred maturity: Two sides of the same coin. American Naturalist 146:625-650.

FISHER, R. A. 1930. The genetical theory of natural selection. Clarendon Press, Oxford.

FRANK, S. A. 1990. Sex allocation theory for birds and mammals. Annual Review Ecology and Systematics 21:13-55.

GowAty, P. A. 1991. Facultative manipulation of sex ratios in birds. Rare or rarely observed? Current Ornithology 8:141-170.

GRIfFITHS, R., AND B. TIWARI. 1993. The isolation of molecular genetic markers for the identification of sex. Proceedings of the National Academy of Sciences USA 90:8324-8326.

HAMILTON, W. D. 1967. Extraordinary sex ratios. Science 156:477-488.

HARRIS, M. P. 1969. Effect of laying date on chick production in Oystercatchers and Herring Gulls. British Birds 62:70-75.

HeG, D. 1999. Life history decisions in Oystercatchers. Ph.D. dissertation, University of Groningen, Groningen, The Netherlands.

Heg, D., B. J. Ens, T. Burke, L. Jenkins, And J. P. KRUIJT. 1993. Why does the typically monogamous Oystercatcher (Haematopus ostralegus) engage in extra-pair copulations? Behaviour 126: 247-289.

Heg, D., B. J. Ens, H. P. van der Jeugd, And L. W. BRUINZEEL. 2000. Local dominance and territorial settlement of nonbreeding Oystercatchers. Behaviour 137:473-530.

HEG, D., AND M. VAN DER VELDE. 2001. Effects of territory quality, food availability and sibling competition on the fledging success of Oystercatchers. Behavioral Ecology and Sociobiology in press.

Koenig, W. D., AND J. L. Dickinson. 1996. Nestling sex-ratio variation in Western Bluebirds. Auk 113:902-910.
Komdeur, J., S. DaAn, J. Tinbergen, And C. MateMAN. 1997. Extreme adaptive modification in sex ratio of the Seychelles Warbler's eggs. Nature 385:522-524.

Leroux, A., And V. Bretagnolle. 1996. Sex ratio variations in broods of Montagu's Harriers Circus pygargus. Journal of Avian Biology 27:63-69.

Lessells, C. M., AND M. I. Avery. 1987. Sex-ratio selection in species with helpers at the nest: Some extensions of the repayment model. American Naturalist 129:610-620.

Lessells, C. M., AND A. C. Mateman. 1998. Sexing birds using random amplified polymorphic DNA (RAPD) markers. Molecular Ecology 7: 187-195.

Lessells, C. M., A. C. Mateman, And J. Visser. 1996. Great Tit hatchling sex ratios. Journal of Avian Biology 27:135-142.

Martin, R., AND A. W. RAdemaKer. 1992. A study of paternal age and sex ratio in sperm chromosome complements. Human Heredity 42:333-336.

Martin, R. H., E. Spriggs, E. Ko, And A. W. RAdeMAKER. 1995. The relationship between paternal age, sex ratios, and aneuploidy frequencies in human sperm, as assessed by multicolor FISH. American Journal of Human Genetics 57:1395-1399.

NorUSIS, M. J. 1990. SPSS/PC+ Advanced statistics 4.0. SPSS, Inc., Chicago, Illinois.

SAMBROOK, J., E. F. FritsCH, AND T. MANiATIS. 1989. Molecular cloning: A laboratory manual, 2nd ed. Cold Spring Harbor Laboratory Press, Cold Spring Harbor, New York.

SiEgEL, S., AND N. J. CASTELlAN. 1988. Nonparametric statistics for the behavioral sciences, 2 nd ed. McGraw-Hill, New York.

STRIJKSTRA, R. J. 1986. Oosterkwelder: Het broedseizoen van de scholekster. M.S. thesis, University of Groningen, Groningen, The Netherlands.

SvensSON, E., AND J.-Å. NILSSON. 1996. Mate quality affects offspring sex ratio in Blue Tits. Proceedings of the Royal Society of London Series B 263: 357-361.

Trivers, R. L., AND D. E. Willard. 1973. Natural selection of parental ability to vary the sex ratio of offspring. Science 179:90-91.

Watson, A., R. Moss, R. PARr, M. D. Mountford, AND P. RotherY. 1994. Kin land ownership, differential aggression between kin and non-kin, and population fluctuations in Red Grouse. Journal of Animal Ecology 63:39-50.

WeAtherheAd, P. J., AND R. Montgomerie. 1995. Local resource competition and sex ratio variation in birds. Journal of Avian Biology 26:168-171.

Westerdahl, H., S. Bensch, B. Hansson, D. HasSELQUIST, AND T. VON SCHANTZ. 1997. Sex ratio variation among broods of Great Reed Warblers Acrocephalus arundinaceus. Molecular Ecology 6: 543-548.

Associate Editor: R. D. Montgomerie 
APPENDIX. Probability of misclassifying the sex of Eurasian Oystercatcher chicks using PCR RAPD markers.

The analysis of the hatchling sex ratio is dependent on the assumption that misclassification of the sexes is negligible. Thus, one has to assess the probability of committing a type 1 error (i.e. falsely rejecting the null hypothesis that the apparently female-specific band is unrelated to sex). Assume that the probability of finding a PCR band $(p)$ is independent of sex. The probability of finding this band in all known females $(n$ ㅇ) and in none of the known males ( $n \hat{\sigma})$ analyzed is given by a function of $p$ and the number of known males and females analyzed:

$$
\mathrm{f}(p)=p^{n \uparrow}(1-p)^{n \hat{n}} \text {. }
$$

The probability of committing a type 1 error, $\mathrm{f}(p)_{\max }$ can be determined by calculating the maximum of the derivative of $\mathrm{f}(p)$ :

$$
\begin{gathered}
\mathrm{f}(p)=n \uparrow \cdot p^{n \uparrow-1} \cdot(1-p)^{n \hat{\jmath}}-n \hat{\sigma} \cdot p^{n \uparrow} \cdot(1-p)^{n \hat{\jmath}-1}=0, \\
\Rightarrow p=\frac{n \hat{\sigma}}{n \uparrow+n \hat{\jmath}}
\end{gathered}
$$

with $f^{\prime \prime}(p)<0$ (it can be shown that $\mathrm{f}(p)=0$ is always a maximum). Thus, by using a number of males and females of known sex $(n \hat{\sigma}$ and $n+), \mathrm{f}(p)_{\max }$ can be calculated. In our analysis, we used 113 individuals of known sex $(n+=56$ and $n \hat{\sigma}=57)$. All females and none of the males had the PCR band. Hence, $p=0.4956$ and $\mathrm{f}(p)_{\max }=9.7 \times 10^{-35}$. Thus, the PCR band is a very reliable indicator of sex. 